\title{
The rise of multiple imputation: a review of the reporting and implementation of the method in medical research
}

Panteha Hayati Rezvan ${ }^{1}$, Katherine J Lee ${ }^{2,3}$ and Julie A Simpson ${ }^{1 *}$

\begin{abstract}
Background: Missing data are common in medical research, which can lead to a loss in statistical power and potentially biased results if not handled appropriately. Multiple imputation (MI) is a statistical method, widely adopted in practice, for dealing with missing data. Many academic journals now emphasise the importance of reporting information regarding missing data and proposed guidelines for documenting the application of Ml have been published. This review evaluated the reporting of missing data, the application of MI including the details provided regarding the imputation model, and the frequency of sensitivity analyses within the Ml framework in medical research articles.

Methods: A systematic review of articles published in the Lancet and New England Journal of Medicine between January 2008 and December 2013 in which MI was implemented was carried out.

Results: We identified 103 papers that used Ml, with the number of papers increasing from 11 in 2008 to 26 in 2013. Nearly half of the papers specified the proportion of complete cases or the proportion with missing data by each variable. In the majority of the articles (86\%) the imputed variables were specified. Of the 38 papers (37\%) that stated the method of imputation, 20 used chained equations, 8 used multivariate normal imputation, and 10 used alternative methods. Very few articles (9\%) detailed how they handled non-normally distributed variables during imputation. Thirty-nine papers (38\%) stated the variables included in the imputation model. Less than half of the papers (46\%) reported the number of imputations, and only two papers compared the distribution of imputed and observed data. Sixty-six papers presented the results from Ml as a secondary analysis. Only three articles carried out a sensitivity analysis following $\mathrm{Ml}$ to assess departures from the missing at random assumption, with details of the sensitivity analyses only provided by one article.

Conclusions: This review outlined deficiencies in the documenting of missing data and the details provided about imputation. Furthermore, only a few articles performed sensitivity analyses following Ml even though this is strongly recommended in guidelines. Authors are encouraged to follow the available guidelines and provide information on missing data and the imputation process.
\end{abstract}

Keywords: Missing data, Multiple imputation, Sensitivity analysis, Reporting

\footnotetext{
* Correspondence: julieas@unimelb.edu.au

${ }^{1}$ Centre for Epidemiology and Biostatistics, Melbourne School of Population and Global Health, The University of Melbourne, Parkville, Melbourne, VIC, Australia

Full list of author information is available at the end of the article
} 


\section{Background}

Missing data are common in clinical and epidemiological studies [1-3], and may arise for a variety of reasons that are beyond the researcher's control. Sometimes an individual refuses to participate in a wave of data collection ('unit non-response'), or does not provide information about a particular measure ('item non-response'). Statistical analyses that exclude individuals with missing data result in estimates with less precision compared with the analysis of all individuals, and more importantly, may lead to biased inference. Applying statistical methods that handle missing data appropriately may reduce the bias and increase the precision of the estimates obtained [3]. One of the main difficulties in the analysis of incomplete data is determining the most appropriate approach to handle the missing data. Several statistical methods have been proposed in the literature for handling missing data [4]. These include the simple approach of excluding all individuals with missing data (termed a complete case analysis (CC)), single imputation methods such as last observation carried forward (LOCF), and more principled methods such as multiple imputation (MI). Each of these approaches makes assumptions regarding the missing data that cannot be verified from the observed data. Thus, researchers are encouraged to carry out a sensitivity analysis to assess the robustness of the results to plausible departures from the missing data assumption made in the main analysis [5-8].

A review of published randomised controlled trials in JAMA, New England Journal of Medicine, BMJ, and the Lancet from July to December 2001, by Wood et al. [3], observed that the majority of papers chose an inadequate approach for handling missing outcome data in the analysis of randomised controlled trials, and that sensitivity analyses were rarely performed to justify the assumptions made in the main analysis. This review also provided recommendations for avoiding and handling missing data. These recommendations included reporting any descriptions of missing data (e.g. proportion of missingness in each treatment arm, difference between key baseline variables between individuals with observed and missing outcomes, etc.), stating the missing data assumptions for the statistical approach selected for handling the missing data, and performing sensitivity analyses around the method chosen to handle the missing data when there is a large proportion of missing data. A more recent review of published clinical trials (2005-2012) with missing longitudinal outcomes by Powney et al. [1] reported ongoing inadequacies in the reporting and handling of missing data. They found that the majority of the published trials did not provide reasons for missingness (drop out) or justification for the methods used to handle missing data. In line with Wood et al. and Powney et al., the Strengthening the Reporting of
Observational Studies in Epidemiology (STROBE) statement published in 2007 [9] recommends that the number of individuals with missing data for each variable of interest should be specified as well as possible reasons for non-participation or non-response at each stage of the study. STROBE also states that the method for handling missing data should be detailed in the statistical methods. A review of publications from cohort studies with exposures measured in multiple follow-up waves by Karahalios et al. [2], points out the continuing use of inappropriate methods of missing data handling and the lack of adherence to the STROBE guidelines. Finally, a report from the National Research Council (NRC) [8], published in 2010, states the necessity of conducting sensitivity analyses using different approaches to deal with missing data to explore the robustness of conclusions to alternative assumptions about the missing data.

Over recent years, multiple imputation (MI) has gained popularity as a powerful statistical tool for handling missing data [10] and is starting to be recommended by journal reviewers [7]. Although MI is appealing and fairly easy to implement in standard statistical software, it can introduce bias if not carried out appropriately [11]. Despite the growth in popularity of MI, a review by Mackinnon [10] highlighted that there was inconsistent reporting of MI in research articles published in major medical journals (i.e. JAMA, New England Journal of Medicine, BMJ, and the Lancet) from the earliest date of full text searching for MI until the end of 2008. Since then, Sterne et al. [5] suggested guidelines for the conduct and reporting of analyses using MI, in which authors are encouraged to document the important aspects of the implementation of the MI procedure in order to assist readers to make informed decisions about the analysis performed.

More recently, it is also starting to become apparent that even when MI is carried out, it may be important to conduct a sensitivity analysis regarding the (untestable) missing at random assumption around MI, since it also makes fairly restrictive assumptions about the missingness [8]. However, it is unclear whether such sensitivity analyses are being carried out after performing MI.

Previous reviews of missing data have generally focused on documenting the handling and reporting of missing outcome data in randomised clinical trials or missing covariate measures in cohort studies with multiple waves of data collection. In this systematic review, our focus is more specifically on assessing the implementation and documentation of MI in both published randomised control trials and observational studies, in addition to the reporting of missing data when using MI. Although we recognise the importance of correct specification of the imputation model in order to provide valid results of MI, we focus on whether a detailed 
description of variables included in the imputation model and information on the imputation method are provided, rather than judging the adequacy of the imputation model.

Our systematic review extends the review proposed by Mackinnon [10] assessing whether the reporting of MI has improved over recent years as the popularity of this approach has increased and guidance has appeared in the literature. Furthermore, this review explores whether researchers are recognising the assumptions made when using MI and are conducting sensitivity analyses within the MI framework to assess the impact of this assumption. To do this, we report a detailed exploration of how MI was carried out and reported within both trials and observational studies that use MI in two high ranking medical journals, the Lancet and the New England Journal of Medicine, from 2008 through 2013.

The rest of this paper is set out as follows: we begin with an overview of the steps involved in performing MI to highlight the detail of reporting required. This is followed by an explanation of the inclusion criteria and extraction details for the systematic review. Finally, we summarise the results of the review, and then end with a discussion and draw conclusions.

\section{Methods}

\section{Implementation of multiple imputation}

MI is a sophisticated but flexible approach for handling missing data and is broadly applicable within a range of standard statistical software packages such as R [12], SAS [13] and Stata [14]. MI proceeds with replicating the incomplete dataset multiple times and replacing the missing data in each replicate with plausible values drawn from an imputation model. The statistical analysis of interest (e.g. a logistic regression of binary outcome on an exposure variable and confounders) is then performed on each completed dataset separately. Finally, a single MI estimate (and its standard error) is calculated by combining the estimates (and standard errors) obtained from each completed dataset using 'Rubin's rules' $[15,16]$. Unlike single imputed methods, MI takes into account the uncertainty associated with the imputed values. The estimated variance of the overall MI estimate allows for within-imputation (i.e. the uncertainty in the estimate within each completed dataset) and betweenimputation (i.e. the uncertainty between the estimates across the completed datasets) variability $[15,16]$.

There are a number of decisions to be made in the imputation stage of MI which can affect the results obtained. It is important to document these decisions so that the readers can be clear about how the investigator performed the imputation and assess the validity of the results. For example, which variables should be included in the imputation model, what imputation method should be used, and how many imputations are required. Once these decisions have been made, it is important to perform diagnostic checks in order to assess the adequacy of the resulting imputation model.

Careful attention is required to select which variables should be included in the imputation model and the form of the variables in order to avoid misspecification of the imputation model and produce biased results. It has been widely recommended to include all variables used in the analysis model (including the outcome variable and any interactions or non-linear terms) in the imputation model to ensure congeniality between the imputation and analysis models. It is also important to include auxiliary variables (i.e. those variables that are not included in the analysis model but are potential predictors of missingness and/or the variable with missing data) in the imputation model which can be used to improve the accuracy of the imputed values $[17,18]$.

Another important decision is the method of imputation. There are several methods in the statistical literature for performing MI. In univariate imputation, where only a single variable has missing data, the imputation model can be tailored to the variable being imputed, for example, a linear regression model for a continuous variable or a logistic regression model for a binary variable. Predictive mean matching (PMM) [19] (where missing data are imputed using the observed values with the closest predictive mean from a linear regression model) is another univariate method for imputing missing data for continuous variables, and is less sensitive to violation of the normality assumption than standard linear regression imputation. In multivariate imputation, where multiple variables have missing data, there are two approaches that are available in standard statistical software. These are MI by chained equations (MICE) (also known as fully conditional specification (FCS)) [20] where separate, conditional univariate imputation models are specified for each variable with missing data, and multivariate normal imputation (MVNI) [21] which uses a joint normal distribution applied to all of the variables with missing data. Both of these approaches are used in practice and it is currently unclear which approach is preferable [21].

With regards to the number of imputations that should be performed, it has been suggested recently to apply a reasonable number of imputations $(>5)$ to avoid producing a large Monte Carlo error [20,22,23]. White et al. [20] argued that the number of imputations should be at least greater than the percentage of the missing data in the analysis (e.g. for $30 \%$ missing data at least 30 imputations should be performed).

The standard application of MI assumes that data are 'Missing at random' (MAR), meaning that the probability of data being missing depends on the observed data but not the missing data. When the underlying missing data 
mechanism is 'Missing completely at random' (MCAR), that is, the probability of missingness is independent of the observed and missing data, MI in most scenarios will be more efficient than CC analysis [24]. Recent literature surrounding MI recommends performing a sensitivity analysis following MI to assess for departures from the MAR assumption since in practice there is no way to identify the real missing data mechanism. The idea of a sensitivity analysis is to specify a range of possible values which measure the departure from MAR and assess the impact of these departures on the MI results. The weighting approach (a selection based method) [25,26], and the pattern-mixture approach $[25,27]$ are two methods that have been proposed in the literature for conducting sensitivity analyses within the MI framework. These methods are not readily accessible in most of the statistical software packages at present; however, SAS has recently extended the MI procedure for conducting sensitivity analyses to the MAR assumption using the pattern-mixture model approach [28]. It is currently unclear how often such sensitivity analyses are conducted.

\section{Inclusion criteria and extraction details for this review}

To explore the conduct and reporting of MI in the current medical literature, we reviewed research articles that were published between January 2008 and December 2013 in the Lancet and New England Journal of Medicine (NEJM) in which MI was implemented. These two leading medical journals were chosen since they were both included in the original review by Mackinnon [10], and their impact factor (i.e. the average number of citations of articles from a published academic journal) over the last six years (2008-2013) remains very high [29]. Additionally, the number of extracted articles that used MI during this period in these two journals was 103, similar to the number of articles reviewed in previously published reviews of reporting and handling of missing data [1-3,10,30,31].

The articles were identified using full-text search for the term "multiple imputation" in each journal's website. There were no restrictions placed on the number of articles or the study design. Any supplementary materials or web appendices provided by the publisher were included in the review. The articles were all extracted and reviewed by one researcher $(P H R)$. For any papers with uncertainty or ambiguity in the information regarding missing data or imputation process, the information was extracted by another researcher (JAS; 25\% of articles), and if required, any discrepancies resolved with a third researcher $(K J L)$. For our systematic review, we followed the PRISMA guidelines for transparent reporting of systematic reviews (see Additional file 1: Table S1).

The articles were classified based on the type of the study design: (1) trials including randomised-controlled trials (RCTs) and non-randomised controlled trials (e.g. Quasi-experimental studies), and (2) observational studies including prospective, retrospective, cross-sectional and case-control studies (see Table 1). The following data were extracted from each study (where possible): the amount of missing data (i.e. proportion of observations with missing data or the proportion of complete cases), details on the MI procedure (including the type of variable(s) imputed, the number of imputed variable (s), the imputation method, the number of imputations, the variables included in the imputation model, the transformations applied to improve the normality of continuous variables, the imputation software used, whether diagnostic checks were employed to assess the imputation model, and whether MI was conducted as a primary or secondary analysis) and whether there were any sensitivity analyses conducted following MI.

Table 1 Number of articles using multiple imputation from January 2008 to December 2013 by type of study

\begin{tabular}{|c|c|c|c|}
\hline \multirow[b]{2}{*}{ Type of studies } & \multicolumn{2}{|c|}{ Journal's name } & \multirow[b]{2}{*}{$\begin{array}{l}\text { All Studies } \\
(n=103)\end{array}$} \\
\hline & $\begin{array}{l}\text { Lancet } \\
(\mathrm{n}=58)\end{array}$ & $\begin{array}{l}\text { New England Journal of Medicine } \\
(n=45)\end{array}$ & \\
\hline \multicolumn{4}{|l|}{ Trials } \\
\hline Randomised controlled trials & 35 & 34 & 69 \\
\hline Non-randomised controlled trials ${ }^{a}$ & 2 & 2 & 4 \\
\hline Total & 37 & 36 & 73 \\
\hline \multicolumn{4}{|l|}{ Observational studies } \\
\hline Prospective studies & 11 & 7 & 18 \\
\hline Retrospective studies $^{b}$ & 6 & 1 & 7 \\
\hline Cross-sectional studies & 3 & 0 & 3 \\
\hline Case-control studies & 1 & 1 & 2 \\
\hline Total & 21 & 9 & 30 \\
\hline
\end{tabular}

${ }^{\mathrm{a}}$ Quasi- experimental studies; ${ }^{\mathrm{b}}$ Retrospective studies- these are studies which performed a retrospective analysis of routinely collected data. 


\section{Results}

Overall, we identified 103 published articles using MI during the study period (Figure 1) [32-134]. Of these articles, 73 (71\%) were trials (see Table 1 and Additional file 2: Table S2).

Figure 2 shows an increasing trend over time (from 2008 to 2013) in the number of articles using MI. This trend appears to be more visible in trials than observational studies. The key findings of this systematic review including the details of reporting of missing data, variables imputed, and MI procedure are summarised in Tables 2, 3 and 4 , respectively

\section{Reporting of missing data}

The characteristics reported regarding the missing data are summarised in Table 2. Overall, 69 papers (67\%) provided some information about the amount of missing data; this includes 46 out of 73 trials (63\%) and 23 out of 30 observations studies (77\%). Of the 69 with information about the amount of missing data, the proportion of complete cases was presented or possible to infer in 41 papers (59\%), and the amount of missing data by variable was reported or inferable in 55 papers (80\%). In those with data available on the proportion of complete cases, this ranged from $28 \%$ to $99 \%$, with a median of $84 \%$. The maximum proportion of missing data for a single variable was $72 \%$.

Very few articles $(n=13,13 \%)$ compared the distribution of participant characteristics (e.g. exposure, outcome, demographic variables) between individuals with complete and incomplete data; of these, 7 provided summary tables. Out of 103 reviewed papers, only 20 studies (19\%) provided an explicit statement regarding the missing data assumption used in the primary analysis (e.g. MCAR or MAR).

\section{Variables imputed}

The characteristics of imputed variables reported in the identified articles are summarised in Table 3. In 89 articles (86\%), imputed variables were directly specified or possible to identify from the text. The number of imputed variables varied from 1 to 60 , with the majority $(n=39)$ imputing missing data in a single variable, 16 imputing missing data for two variables and 27 imputing missing data for more than two variables. In the remaining 7 articles the number of imputed variables could not be determined.

The majority of trials $(55 / 73,75 \%)$ imputed incomplete outcome variables, while only a few observational studies $(9 / 30,30 \%)$ imputed incomplete outcomes. In contrast, imputing missing data in covariates was more common in observational studies ( $\mathrm{n}=21,70 \%)$, but less common in trials $(n=13,18 \%)$. Just over half of the studies that imputed covariates imputed only one or two covariates (18 out of 34 ).

\section{Imputation details}

The details of the imputation process extracted from the identified articles are summarised in Table 4. Of the 103 articles, 40 (39\%) provided no details of the imputation method, variables used in the imputation model or the number of imputations. Where the imputation method was clearly specified (38/103, 37\%), 20 papers (53\%) used MICE, 8 papers (21\%) used MVNI, and one article (3\%) used PMM. Two papers applied MICE as well as PMM, and the remaining 7 papers, used $\mathrm{MI}$ on the basis of propensity score or regression-based imputation. For the two main imputation methods, 12 out of 20 papers for MICE, and 5 out of 8 papers for MVNI imputed multiple variables with missing data.

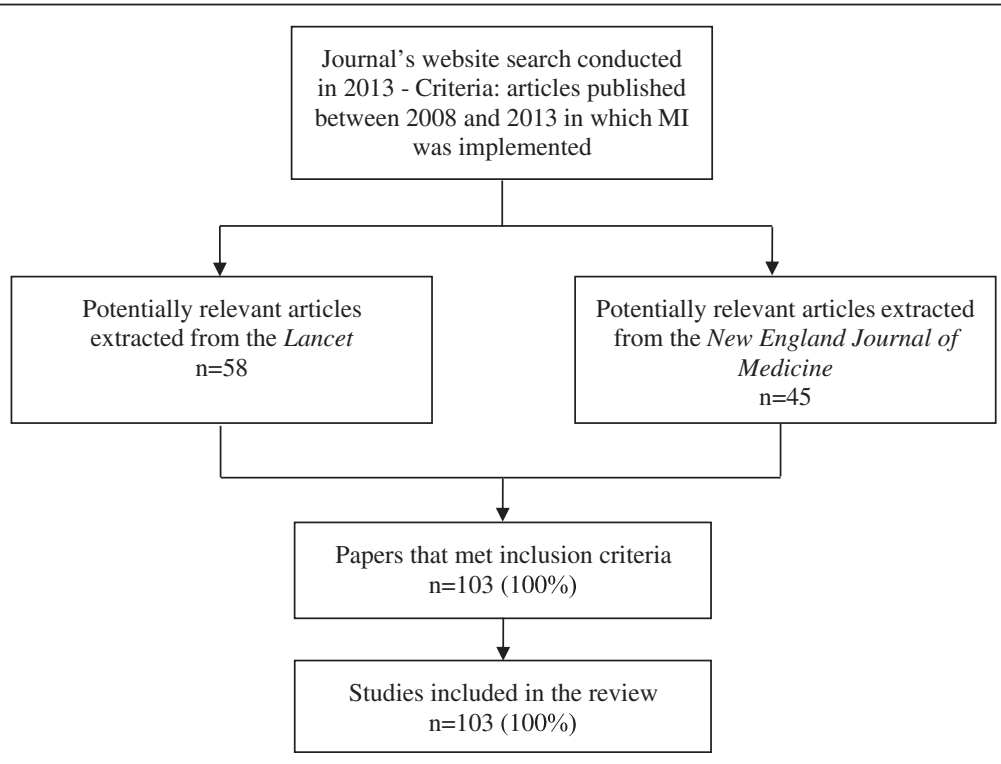

Figure 1 Search results. 


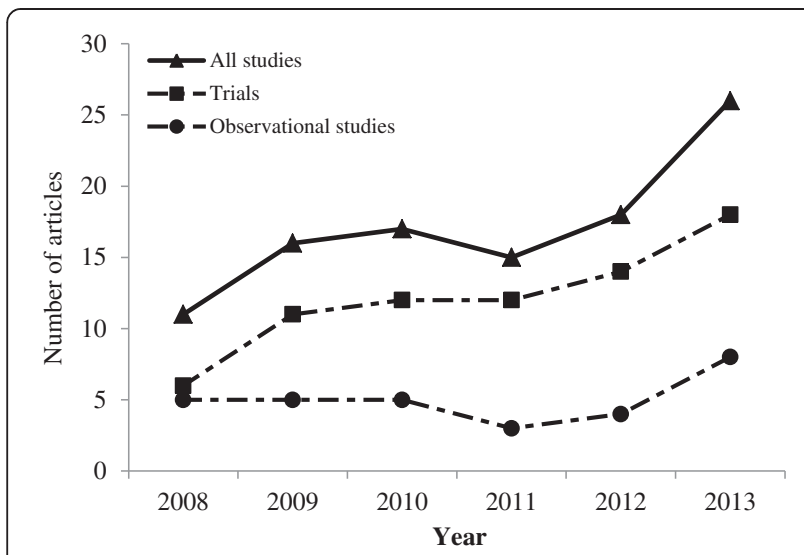

Figure 2 Number of articles in the Lancet and New England Journal of Medicine that used MI: overall and by study type.

Although the majority of papers did not explicitly state the imputation method used, this could be inferred in an additional 21 articles using the version of the imputation software (e.g. MI under chained equations was the only multivariable command available in Stata 10 and earlier versions), the default programme (e.g. IVEware, SAS callable software application implements MI using chained equations), or specific procedure (e.g. SAS Proc MI via MCMC algorithm assumes multivariate normal distribution for implementing $\mathrm{MI}$ ).

Twelve of the articles (12\%) transformed non-normal variables prior to imputation. The logarithm $(\log )$ transformation was the most commonly reported method for handling non-normally distributed variables $(n=8)$; one article used the logit transformation and the remaining 3 articles referred to normalising transformations $(n=2)$ or mentioned that a transformation was used if appropriate $(\mathrm{n}=1)$.

Only 39 of the articles (38\%) specified the variables included in the imputation model. Of these, in 10 articles the imputation model included auxiliary variables, in 4 the imputation model included interaction terms, and in 5 the imputation model included auxiliary variables and interactions. In the remaining 20 articles, no further information was provided on whether the variables included in the imputation model were auxiliary variables or interaction terms. Only a few trials $(n=5)$ stated that they imputed the missing data in each arm separately.

Less than half of the articles $(n=47 / 103,46 \%)$ reported the number of imputations used. The number of imputations ranged from $<=5$ (11 papers) to $>100$ ( 3 papers), with nearly half of the papers $(n=23)$ using 10 to 50 imputations.

Only 2 studies (2\%) carried out any diagnostic checks of their imputation model, both of which compared the distribution of observed and imputed values. Differences between the results from a complete case analysis (or LOCF) and MI were presented in 62 articles $(60 \%)$.

Seventy-six articles (74\%) stated the software in which the MI was implemented; SAS $(n=33)$, Stata $(n=27)$, and $R(n=12)$ were the commonly most used packages.

\section{Analysis status of $\mathrm{MI}$}

In 38 studies (37\%) MI was used as the primary analysis and in 66 studies (64\%) MI was used as a secondary analysis. Where MI was implemented as a secondary analysis, complete case analysis was the most common method for handling missing data in the primary analysis (62 out of 66 articles).

Finally, of the 103 papers reviewed, only 3 papers (3\%) performed a sensitivity analysis following MI to investigate the robustness of the MI estimate to departures from the MAR assumption. Of these, only one paper provided details about the sensitivity analysis approach. The other two papers gave no information on the method used in the sensitivity analysis.

Table $\mathbf{2}$ Reporting of missing data in articles using multiple imputation

\begin{tabular}{|c|c|c|c|}
\hline \multirow{4}{*}{ Characteristics reported } & \multicolumn{2}{|c|}{ Type of studies } & \multirow{4}{*}{$\begin{array}{l}\text { All studies } \\
N(\%)^{*} \\
(n=103)\end{array}$} \\
\hline & Trials & Observational studies & \\
\hline & $\mathrm{N}(\%)^{*}$ & $\mathbf{N}(\%)^{*}$ & \\
\hline & $(n=73)$ & $(n=30)$ & \\
\hline \multicolumn{4}{|l|}{ Missingness } \\
\hline Availability of any information about the amount of missing data/complete cases & $46(63)$ & $23(77)$ & $69(67)$ \\
\hline Proportion of complete cases was stated/available & $31(42)$ & $10(33)$ & $41(40)$ \\
\hline Median [Range] \% complete cases & 88 [47-99] & $41[28-74]$ & 84 [28-99] \\
\hline Proportion of missing by each variable was stated/available & $36(49)$ & $19(63)$ & $55(53)$ \\
\hline Assessed differences between individuals with complete and incomplete data in text? & $8(11)$ & $5(17)$ & $13(13)$ \\
\hline Provided a table & 3 & 4 & 7 \\
\hline Statement regarding missing data mechanism assumed in the analysis & $13(18)$ & $7(23)$ & $20(19)$ \\
\hline
\end{tabular}

*Unless otherwise stated. 
Table 3 Reporting of variables imputed in articles using multiple imputation

\begin{tabular}{|c|c|c|c|}
\hline \multirow{4}{*}{ Characteristics reported } & \multicolumn{2}{|c|}{ Type of studies } & \multirow{4}{*}{$\begin{array}{l}\text { All studies } \\
N(\%)^{*} \\
(n=103)\end{array}$} \\
\hline & Trials & Observational studies & \\
\hline & $\mathrm{N}(\%)^{*}$ & $\mathbf{N}(\%)^{*}$ & \\
\hline & $(n=73)$ & $(n=30)$ & \\
\hline \multicolumn{4}{|l|}{ Variables imputed } \\
\hline Variables imputed specified/available & $61(84)$ & $28(93)$ & $89(86)$ \\
\hline \multicolumn{4}{|l|}{ Number of variable(s) imputed } \\
\hline 1 & 31 & 8 & 39 \\
\hline 2 & 9 & 7 & 16 \\
\hline$>2$ & 17 & 10 & 27 \\
\hline Unclear $^{\mathrm{a}}$ & 4 & 3 & 7 \\
\hline \multicolumn{4}{|l|}{ Outcome variable imputed } \\
\hline Yes & $55(75)$ & $9(30)$ & $64(62)$ \\
\hline Not stated & $12(16)$ & $2(7)$ & $14(14)$ \\
\hline No & $6(8)$ & $19(63)$ & $25(24)$ \\
\hline \multicolumn{4}{|l|}{ Type of outcome variable imputed } \\
\hline Numerical & 31 & 6 & 37 \\
\hline Categorical & 16 & 2 & 18 \\
\hline Numerical and categorical & 8 & 1 & 9 \\
\hline \multicolumn{4}{|l|}{ Number of imputed outcome variables } \\
\hline 1 & 30 & 6 & 36 \\
\hline 2 & 10 & 1 & 11 \\
\hline$>2^{\mathrm{b}}$ & 12 & 2 & 14 \\
\hline Unclear $^{\mathrm{a}}$ & 3 & 0 & 3 \\
\hline \multicolumn{4}{|l|}{ Covariate imputed } \\
\hline Yes & $13(18)$ & $21(70)$ & $34(33)$ \\
\hline Not stated & $12(16)$ & $2(7)$ & $14(14)$ \\
\hline No & $48(66)$ & $7(23)$ & $55(53)$ \\
\hline \multicolumn{4}{|l|}{ Type of covariates imputed } \\
\hline Numerical & 6 & 4 & 10 \\
\hline Categorical & 3 & 8 & 11 \\
\hline Numerical and categorical & 3 & 8 & 11 \\
\hline Unclear ${ }^{\mathrm{a}, \mathrm{c}}$ & 1 & 1 & 2 \\
\hline \multicolumn{4}{|l|}{ Number of imputed covariates } \\
\hline 1 & 6 & 3 & 9 \\
\hline 2 & 2 & 7 & 9 \\
\hline$>2$ & 5 & 8 & 13 \\
\hline Unclear $^{a}$ & 1 & 3 & 4 \\
\hline
\end{tabular}

*Unless otherwise stated.

${ }^{a}$ Authors provided a generic statement regarding the imputed variables (e.g. the missing data in the covariates were imputed), and did not explicitly specify which outcome or covariate with missing data was imputed, so the number or type of imputed variables could not be verified.

${ }^{\mathrm{b}}$ One article [128] imputed missing data in 5 incomplete variables for two questionnaires recorded at 6 different waves of data collection (i.e. 60 imputed variables).

' In one paper [98], the use of MI for imputing missing data in the covariates was derived from the cited reference, so the data type of imputed variables was not clear.

\section{Discussion}

Missing data frequently occur in clinical and epidemiological research. MI is now recognised as a flexible and efficient approach to deal with missing data and is widely employed by investigators in a wide variety of settings. In this review, we show that the application of MI has increased in research articles published in the Lancet and NEJM over the 5-year period from 2008 to 2013. 
Table 4 Reporting of MI procedure in articles using multiple imputation

\begin{tabular}{|c|c|c|c|}
\hline \multirow{4}{*}{ Characteristics reported } & \multicolumn{2}{|c|}{ Type of studies } & \multirow{4}{*}{$\begin{array}{l}\text { All studies } \\
\mathrm{N}(\%)^{*} \\
(\mathrm{n}=103)\end{array}$} \\
\hline & Trials & Observational studies & \\
\hline & $\mathrm{N}(\%)^{*}$ & $\mathrm{~N}(\%)^{*}$ & \\
\hline & $(n=73)$ & $(n=30)$ & \\
\hline \multicolumn{4}{|l|}{ Imputation details } \\
\hline Any imputation details provided ${ }^{a}$ & $60(82)$ & $27(90)$ & $87(85)$ \\
\hline Imputation method stated & $29(40)$ & $9(30)$ & $38(37)$ \\
\hline MI using chained equations (MICE) & 14 & 6 & 20 \\
\hline MI using multivariate normal model $(\mathrm{MVNI})^{\mathrm{b}}$ & 7 & 1 & 8 \\
\hline Ml using predictive mean matching (PMM) & 1 & 0 & 1 \\
\hline Ml using regression-based imputation ${ }^{c}$ & 4 & 1 & 5 \\
\hline MI using MICE \& PMM ${ }^{d}$ & 1 & 1 & 2 \\
\hline Ml using propensity score & 1 & 0 & 1 \\
\hline MI using propensity score or regression modelling ${ }^{e}$ & 1 & 0 & 1 \\
\hline General procedure/command specified & $5(7)$ & $2(7)$ & $7(7)$ \\
\hline Proc Ml & 4 & 1 & 5 \\
\hline Ml command & 0 & 1 & 1 \\
\hline Model-based $\mathrm{MI}^{\mathrm{f}}$ & 1 & 0 & 1 \\
\hline Imputation method inferred & $11(15)$ & $10(33)$ & $21(20)$ \\
\hline MICE (SAS- IVEware) & 1 & 2 & 3 \\
\hline MICE (Stata- pre V11) & 1 & 2 & 3 \\
\hline MICE (Multiple package ${ }^{9}$ ) & 1 & 0 & 1 \\
\hline MVNI (SAS- pre V9.3-imputed more than 1 variable) & 5 & 1 & 6 \\
\hline MVNI (R-Amelia II) & 0 & 2 & 2 \\
\hline MVNI (S-plus) & 2 & 0 & 2 \\
\hline Regression-based imputation (SAS pre V9.3-imputed 1 categorical variable) & 1 & 3 & 4 \\
\hline Non-normal variables transformed prior to imputation & $6(8)$ & $6(20)$ & $12(12)$ \\
\hline Log transformation ${ }^{\mathrm{h}}$ & 4 & 4 & 8 \\
\hline Logit transformation & 0 & 1 & 1 \\
\hline General comment about applying normalising transformation & 2 & 1 & 3 \\
\hline Provided details on the variables included in the imputation model & $26(36)$ & $13(43)$ & $39(38)$ \\
\hline Included auxiliary variable(s) & 6 & 4 & 10 \\
\hline Included interaction term(s) & 2 & 2 & 4 \\
\hline Included auxiliary variable and interaction & 3 & 2 & 5 \\
\hline No information provided on auxiliary variables and interaction terms & 15 & 5 & 20 \\
\hline Number of imputations & $28(38)$ & $19(63)$ & $47(46)$ \\
\hline$\leq 5$ & 8 & 3 & 11 \\
\hline 10 & 6 & 3 & 9 \\
\hline $11-50$ & 8 & 6 & 14 \\
\hline 100 & 4 & 6 & 10 \\
\hline$>100$ & 2 & 1 & 3 \\
\hline Carried out diagnostic checks of the imputation model ${ }^{i}$ & $0(0)$ & $2(7)$ & $2(2)$ \\
\hline Assessed differences between results obtained from CC/LOCF and Ml in the text/table & $45(62)$ & $17(57)$ & $62(60)$ \\
\hline
\end{tabular}


Table 4 Reporting of MI procedure in articles using multiple imputation (Continued)

\begin{tabular}{|c|c|c|c|}
\hline \multicolumn{4}{|l|}{ Software details } \\
\hline Imputation software stated ${ }^{k, 1}$ & $51(70)$ & $25(83)$ & $76(74)$ \\
\hline SAS & 23 & 10 & 33 \\
\hline Stata & 18 & 9 & 27 \\
\hline $\mathrm{R}$ & 6 & 6 & 12 \\
\hline Other packages (SOLAS, S-plus, SPSS) & 4 & 0 & 4 \\
\hline \multicolumn{4}{|l|}{ Analysis status of MI } \\
\hline MI used in the primary analysis & $26(36)$ & $12(40)$ & $38(37)$ \\
\hline Ml used as a secondary analysis & $47(64)$ & $19(63)$ & $66^{1}(64)$ \\
\hline \multicolumn{4}{|c|}{ Methods used for primary analysis if MI applied as a secondary analysis } \\
\hline Complete case analysis $(C C)^{m, n}$ & 43 & 19 & 62 \\
\hline Sensitivity analysis following MI & $3(4)$ & $0(0)$ & $3(3)$ \\
\hline Pattern-mixture model approach & 1 & 0 & 1 \\
\hline Selection model approach & 0 & 0 & 0 \\
\hline Performed but the method not stated ${ }^{\circ}$ & 2 & 0 & 2 \\
\hline
\end{tabular}

*Unless otherwise stated.

Abbreviations: MI- multiple imputation, MICE- multiple imputation by chained equations, MVNI- multivariate normal imputation, PMM- predictive mean matching, MCMC- Markov chain Monte Carlo, CC- complete case, LOCF- last observation carried forward.

${ }^{a}$ Any information provided by the authors with regard to the imputation process. Note: a general procedure/command stated by the authors, and the imputation methods that were inferred by the reviewers are not included in this category.

${ }^{b}$ In five articles $[35,61,68,90]$ Ml via MCMC algorithm was used for imputing missing data.

In three articles [40,47,84], logistic regression method and in two articles [39,113], linear regression method were stated as a imputation method for handling missing data.

${ }^{\mathrm{d}}$ Two articles [61,93] imputed one or two variables with missing data under PMM (because of non-normality), and imputed other incomplete variables under MICE.

${ }^{\mathrm{e}}$ One article [91] stated that MI was used on the basis of either propensity scoring or regression modelling for imputation of missing data in the primary and secondary outcome measures.

fOne article [51] stated that model-based MI was used to account for missing data in the clinical outcome.

IIn one article [77] multiple packages were used for the analyses, i.e. SPSS version 15.0 and Stata version 10.1. The default imputation method in either of these packages (given the specified versions) was chained equations.

hone article [93] used both the square root and log transformations for non-normally distributed variables.

'Both articles $[82,130]$ compared the observed and imputed data.

'The Ml estimates were not provided in 6 articles [34,37,81,85,87,120], instead a comparison of the results between the different approaches for dealing with the missing data was commented on in the text (e.g. the analysis of complete cases and the imputed data provided the same results).

${ }^{\mathrm{k}}$ For eight articles $[59,77,81,88,94,96,115,127]$ it was not possible to extract this information because multiple packages for the statistical analyses were mentioned with no explicit statement regarding which package was used for imputation.

'Those articles that did not provide the name of the imputation software (R, Stata, SAS, etc.), but instead gave the name of the procedure/application used for imputing missing data (e.g. Amelia II, IVEware) were also included here.

mOne article [99] used Ml as well as CC for primary analysis to impute the missing confounder values (with no imputation of missing data in the exposure and outcome), and used Ml again as a sensitivity analysis to impute missing data in all confounders and the outcome (but not the exposure), as well as a CC.

${ }^{\mathrm{n}}$ Two articles $[40,100]$ used LOCF for the secondary analysis as well as Ml; one of them described the Ml as a sensitivity analysis.

${ }^{\circ} \mathrm{A}$ general statement was made about performing a sensitivity analysis but the results of the details were not provided.

This finding demonstrates the growing popularity of MI since the previous review by Mackinnon [10], that also observed a significant increase in use of MI between 2005 and 2008 in articles published in four major medical journals.

We identified 103 studies from these two high ranking journals that implemented MI in the statistical analyses. These papers represent approximately 3\% of the total 3815 original research articles published between January 2008 and December 2013 (i.e. 58/1705 papers in the Lancet and $45 / 2110$ papers in the NEJM) [29]. Since the majority of the identified papers were trials where the missing outcome variables were imputed, we re-emphasise the need for trialists to consider schemes to encourage maximum follow-up of participants at the pilot phase and design stage of the study [6]. This may minimize the amount and potential impact of missing data.
Despite the presence of guidelines and recommendations for clear documentation around the reporting of missing data $[1-3,5,9,10,30,31]$, there remains poor reporting of the amount of missing data with only half of the articles in this review providing the proportion of the complete cases or the proportion of missing data for each variable of interest in the manuscript. This observation is consistent with the finding of Mackinnon [10], who found that just over half of the articles did not provide any information about the amount of missing data. When performing MI, one should clearly report the amount of missing data for each variable included in the analysis, or at least, state the number of cases with complete observations. Providing this information helps the reader to assess the validity of the results since a larger proportion of missing data may introduce a greater bias in the analysis. 
Exploring differences between individuals with complete and incomplete data can be used to examine the validity of the MCAR assumption; however, few articles compared the characteristics of participants with complete and incomplete data. Moreover, less than one-third of the published papers had a statement about the assumption made regarding the missing data within the analysis. Collecting information on reasons for missing data is very valuable and can help determine the most plausible assumption underlying the missing data. Since the standard application of MI assumes that data are MAR, it is important for investigators to acknowledge this assumption when using MI and justify it. Given it is not possible to assess the validity of the MAR assumption, it is also important to assess the sensitivity of the results to this assumption by making alternative assumptions about the missing data, for example that data are missing not at random (MNAR), that is allowing the missingness to depend on the unobserved data.

Previously published reviews and guidelines of handling missing data suggest the importance of providing adequate information on the imputation process used in MI $[5,10]$. However, this was one of the greatest weaknesses we found in our review. While details of the imputation method were available in just over one-third of the articles, this information was often not explicitly stated and was instead derived from the details of the imputation software. It is important that the researcher performing MI recognise the impact of decisions made in setting up the imputation model on the MI results. Presenting details on how MI was carried out may provide insight regarding the distributional assumptions made for variables with missing data, so that the validity of the results can be assessed. Detailed information, required for all statistical analyses, also ensures reproducibility of the results.

In our review, approximately one-third of articles clearly specified the variables included in the imputation model, and only half of these commented on the inclusion of auxiliary variables or interaction terms. Obtaining information on auxiliary variables that are highly associated with the missingness mechanism and the incomplete variable, and incorporating them into the imputation model can make the MAR assumption more plausible. In addition, it can improve the accuracy of the imputations, and as a result, may reduce the bias and increase the precision of the estimates.

In line with the Mackinnon's review [10], we found that less than half of the articles stated the number of imputations, with nearly half using 10 to 50 imputations. As mentioned earlier, applying an adequate number of imputations is recommended in order to avoid producing a large Monte Carlo error. Therefore, stating the number of imputations along with the percentage of missing data within each variable can help readers make a better judgment about the accuracy of the MI results.

Despite the recent acknowledgement about the importance of carrying out diagnostic checks of imputation models [135-138], only two articles carried out any form of diagnostic checking, both of which compared the distribution of the observed and imputed values.

The importance of reporting and explaining differences between the results of complete case analysis and MI was pointed out by Sterne et al. [5], and have been recently emphasised by Powney et al. [1] in a supporting guidance for handling missing data in longitudinal trials. However, our review shows that just under two-third of articles compared the estimates derived from a complete case analysis and MI.

While the findings of the paper published by Mackinnon [10] showed that MI was implemented as the primary analysis in just over half of the identified articles, we observed that MI was adopted as the secondary analysis in just under two-third of the studies, with complete case analysis generally being used as the primary analysis.

Disappointingly, the majority of the reviewed articles failed to recognise the importance of conducting sensitivity analyses regarding the MAR assumption following MI. More specifically, only three articles explored the sensitivity of the results to departures from MAR, of which only one article [128] provided details of the estimates derived. We understand that there is a lack of explicit guidelines in the literature for conducting sensitivity analyses within the MI framework. The development of this area is a subject of ongoing research. We believe that performing sensitivity analyses regarding the MAR assumption post-MI should be regarded as an essential part of the analysis to assess the robustness of the conclusions to plausible departures from this critical assumption.

It is important to acknowledge that many journals have strict word limits for original research articles, including a maximum number of tables and figures that can be included. For example, in the Lancet the word limit is 3000 words, and in the NEJM it is 2700 words for Original and Special articles. This makes it difficult to include all of the details surrounding the imputation procedure. However, this information can be reported in a previously published "baseline" or "protocol" paper, or included as online supplements, especially in such journals with very tight word limits. In his recent paper, Ware [7] suggested some improvements in journal policies regarding the reporting of clinical trials and observational studies in presence of missing data, in addition to the documentation of details about the methods for handling missing data. As noted by Ware [7], journal authors will be required to state clearly the assumptions made about the missing data and justify them, and may be requested to conduct sensitivity analyses where appropriate. In addition, 
authors will be expected to provide supplementary appendices in which the details of the method for analysis of missing data are clearly explained. It is important to note that while just over two-thirds of the identified articles in this review included supplementary materials or web appendices, very few articles provided a complete description of the missing data and the MI procedure according to the available reporting guidelines.

\section{Conclusions}

This review of articles published (in the Lancet and NEJM) in the past 5 years (2008-2013) has highlighted the continued inadequacy of reporting information about missing data and the MI procedure in research articles that use MI. Although our review showed improvements in reporting since the Mackinnon review of articles published between 1994 (earliest MI publication) and 2008, many articles are still not following the guidelines and recommendations for the reporting of missing data and statistical analyses using MI.

It is essential that researchers are aware of the issues that may arise when implementing MI, and more importantly that biased and imprecise results may be obtained if the imputation model is misspecified. Authors are encouraged to provide information on missing data, include details of the analyses when using MI, explore the impact of missing data on their results, and assess the sensitivity of the MI results to plausible departures from the MAR assumption. Providing detailed information on all of the above allows readers to make an informed decision about the quality of the study results, appropriateness of the imputation process, and validity of the results obtained from MI.

\section{Additional files}

Additional file 1: Table S1. PRISMA checklist for reporting systematic reviews.

Additional file 2: Table S2. Details of the articles included in the systematic review and the corresponding reference list [32-134].

\section{Abbreviations \\ CC: Complete case; LOCF: Last observation carried forward; MAR: Missing at random; MCAR: Missing completely at random; MCMC: Markov chain Monte Carlo; MI: Multiple imputation; MICE: Multivariate imputation by chained equations; MNAR: Missing not at random; MVNI: Multivariate normal imputation; NEJM: New England Journal of Medicine; PMM: Predictive mean matching; RCT: Randomised controlled trial; STROBE: Strengthening the Reporting of Observational Studies in Epidemiology.}

\section{Competing interests}

The authors declare that they have no competing interests.

\section{Authors' contributions}

PHR extracted and reviewed the articles, and drafted the manuscript. JAS conceived of the review, resolved any uncertainty encountered by PHR and helped with drafting of the manuscript. KJL provided feedback on the design of the protocol and revised draft versions of the manuscript. All authors read and approved the final manuscript.

\section{Acknowledgements}

This work was supported by funding from the National Health and Medical Research Council: a Centre of Research Excellence grant, ID 1035261, awarded to the Victorian Centre of Biostatistics (ViCBiostat), and Career Development Fellowship ID 1053609(KJL). PHR is funded by a University of Melbourne International Research Scholarship.

\section{Author details}

${ }^{1}$ Centre for Epidemiology and Biostatistics, Melbourne School of Population and Global Health, The University of Melbourne, Parkville, Melbourne, VIC, Australia. ${ }^{2}$ Clinical Epidemiology and Biostatistics Unit, Murdoch Childrens Research Institute, Parkville, Melbourne, VIC, Australia. ${ }^{3}$ Department of Paediatrics, The University of Melbourne, Parkville, Melbourne, VIC, Australia.

Received: 14 November 2014 Accepted: 18 March 2015

Published online: 07 April 2015

\section{References}

1. Powney M, Williamson P, Kirkham J, Kolamunnage-Dona R. A review of the handling of missing longitudinal outcome data in clinical trials. Trials. 2014;15(1):1-19.

2. Karahalios A, Baglietto L, Carlin JB, English DR, Simpson JA. A review of the reporting and handling of missing data in cohort studies with repeated assessment of exposure measures. BMC Med Res Methodol. 2012;12:96-105.

3. Wood AM, White IR, Thompson SG. Are missing outcome data adequately handled? A review of published randomized controlled trials in major medical journals. Clin Trials. 2004;1(4):368-76.

4. Schafer JL, Graham JW. Missing data: Our view of the state of the art. Psychol Methods. 2002;7(2):147-77.

5. Sterne JAC, White IR, Carlin JB, Spratt M, Royston P, Kenward MG, et al. Multiple imputation for missing data in epidemiological and clinical research: potential and pitfalls. BMJ. 2009;338:b2393.

6. Little RJ, D'Agostino R, Cohen ML, Dickersin K, Emerson SS, Farrar JT, et al. The Prevention and Treatment of Missing Data in Clinical Trials. N Engl J Med. 2012;367(14):1355-60.

7. Ware JH, Harrington D, Hunter DJ, D'Agostino RB. Missing Data. N Engl J Med. 2012;367(14):1353-4.

8. National Research Council. Panel on Handling Missing Data in Clinical Trials, Committee on National Statistics, Division of Behavioral and Social Sciences and Education: The prevention and treatment of missing data in clinical trials. Washington, D.C: National Academies Press; 2010.

9. Von E, Erik A, Egger DG, Matthias P, Gøtzsche SJ, Vandenbroucke PC, et al. The Strengthening the Reporting of Observational Studies in Epidemiology (STROBE) Statement: guidelines for reporting observational studies. Bull World Health Organ. 2007;85(11):867-72.

10. Mackinnon A. The use and reporting of multiple imputation in medical research - a review. J Intern Med. 2010;268(6):586-93.

11. Lee KJ, Carlin JB. Recovery of information from multiple imputation: a simulation study. Emerging Themes in Epidemiology. 2012;9(1):3-12.

12. R Development Core Team: R: A language and environment for statistical computing, reference index version 2.2.1. Vienna, Austria.ISBN 3-900051-07-0. URL http://www.R-project.org: R Foundation for Statistical Computing; 2005.

13. SAS Institute Inc. PROC MI. SAS Procedures Giude, Version 9.2. Cary, NC: SAS Institute Inc; 2008.

14. StataCorp. Stata Statistical Software: Release 12. College Station, TX: Stata Corp LP; 2009.

15. Little RJA, Rubin DB. Statistical analysis with missing data/Roderick J.A. Little, Donald B. Rubin. Hoboken, N.J: Wiley, c2002; 2nd ed; 2002.

16. Rubin DB. Multiple imputation for nonresponse in surveys/Donald B. Rubin. New York: Wiley, c1987; 1987.

17. Graham JW. Missing data [electronic resource] : analysis and design/John W. Graham. New York, NY: Springer, c2012; 2012.

18. Lee KJ, Simpson JA. Introduction to multiple imputation for dealing with missing data. Respirology. 2014;19(2):162-7.

19. Schenker N, Taylor J. Partially parametric techniques for multiple imputation. Comput Stat Data Anal. 1996;22(4):425-46.

20. White IR, Royston P, Wood AM. Multiple imputation using chained equations: Issues and guidance for practice. Stat Med. 2011;30(4):377-99.

21. Lee KJ, Carlin JB. Multiple imputation for missing data: fully conditional specification versus multivariate normal imputation. Am J Epidemiol. 2010;171(5):624-32. 
22. Royston P. Multiple imputation of missing values. STATA JOURNAL. 2004;4 (3):227-41.

23. Van Buuren S. Flexible Imputation of Missing Data: 1st ed. Hoboken: Taylor and Francis; 2012

24. White IR, Carlin JB. Bias and efficiency of multiple imputation compared with complete-case analysis for missing covariate values. Stat Med. 2010;29 (28):2920-31.

25. Carpenter JR, Kenward MG. Multiple imputation and its application/James R. Carpenter and Michael G. Kenward. 1st ed. Chichester: Wiley; 2013.

26. Carpenter JR, Kenward MG, White IR. Sensitivity analysis after multiple imputation under missing at random: a weighting approach. Stat Methods Med Res. 2007;16(3):259-75.

27. Ratitch B, O'Kelly M, Tosiello R. Missing data in clinical trials: from clinical assumptions to statistical analysis using pattern mixture models. Pharm Stat. 2013;12(6):337

28. Yuan Y: Sensitivity Analysis in Multiple Imputation for Missing Data. In Proceedings of the SAS Global Forum 2014 Conference:[http://support.sas. com/resources/papers/proceedings14/SAS270-2014.pdf]

29. 2014 Journal Citation Reports ${ }^{\circledast}$ Science Edition (Thomson Reuters, 2014) [http://thomsonreuters.com/journal-citation-reports]

30. Klebanoff MA, Cole SR. Use of multiple imputation in the epidemiologic literature. Am J Epidemiol. 2008;168(4):355-7.

31. Burton A, Altman D. Missing covariate data within cancer prognostic studies: a review of current reporting and proposed guidelines. $\mathrm{Br} \mathrm{J}$ Cancer. 2004;91(1):4-8

32. Abdulla S, Sagara I, Borrmann S, D’Alessandro U, González R, Hamel M, et al. Efficacy and safety of artemether-lumefantrine dispersible tablets compared with crushed commercial tablets in African infants and children with uncomplicated malaria: a randomised, single-blind, multicentre trial. Lancet. 2008:372(9652):1819-27.

33. Acker MA, Parides MK, Perrault LP, Moskowitz AJ, Gelijns AC, Voisine P, et al. Mitral-valve repair versus replacement for severe ischemic mitral regurgitation. N Engl J Med. 2014;370(1):23-32

34. Alio AP, Nana PN, Salihu HM. Spousal violence and potentially preventable single and recurrent spontaneous fetal loss in an African setting: crosssectional study. Lancet. 2009;373(9660):318-24.

35. Ang KK, Harris J, Wheeler R, Weber R, Rosenthal DI, Nguyen-Tân PF, et al. Human papillomavirus and survival of patients with oropharyngeal cancer. N Engl J Med. 2010;363(1):24-35.

36. Armstrong PW, Gershlick AH, Goldstein P, Wilcox R, Danays T, Lambert $Y$, et al. Fibrinolysis or Primary PCI in ST-Segment Elevation Myocardial Infarction. N Engl J Med. 2013;368(15):1379-87.

37. Beasley R, Clayton T, Crane J, Von Mutius E, Lai CK, Montefort S, et al. Association between paracetamol use in infancy and childhood, and risk of asthma, rhinoconjunctivitis, and eczema in children aged 6-7 years: analysis from Phase Three of the ISAAC programme. Lancet. 2008;372(9643):1039-48.

38. Bergenstal RM, Tamborlane WV, Ahmann A, Buse JB, Dailey G, Davis SN, et al. Effectiveness of Sensor-Augmented Insulin-Pump Therapy in Type 1 Diabetes. N Engl J Med. 2010;363(4):311-20.

39. Bergenstal RM, Klonoff DC, Garg SK, Bode BW, Meredith M, Slover RH, et al. Threshold-Based Insulin-Pump Interruption for Reduction of Hypoglycemia. N Engl J Med. 2013;369(3):224-32.

40. Boonen S, Reginster J, Kaufman J, Lippuner K, Zanchetta J, Langdahl B, et al. Fracture Risk and Zoledronic Acid Therapy in Men with Osteoporosis. N Engl J Med. 2012;367(18):1714-23.

41. Brott TG, Hobson II RW, Howard G, Roubin GS, Clark WM, Brooks W, et al. Stenting versus endarterectomy for treatment of carotid-artery stenosis. N Engl J Med. 2010;363(1):11-23.

42. Buchbinder SP, Mehrotra DV, Duerr A, Fitzgerald DW, Mogg R, Li D, et al. Efficacy assessment of a cell-mediated immunity HIV-1 vaccine (the Step Study): a double-blind, randomised, placebo-controlled, test-of-concept trial. Lancet. 2008;372(9653):1881-93.

43. Buse JB, Rosenstock J, Sesti G, Schmidt WE, Montanya E, Brett JH, et al. Liraglutide once a day versus exenatide twice a day for type 2 diabetes: a 26-week randomised, parallel-group, multinational, open-label trial (LEAD-6). Lancet. 2009:374(9683):39-47.

44. Carlsson LMS, Peltonen M, Ahlin S, Anveden Å, Bouchard C, Carlsson B, et al. Bariatric Surgery and Prevention of Type 2 Diabetes in Swedish Obese Subjects. N Engl J Med. 2012;367(8):695-704.

45. Caroli A, Perico N, Perna A, Antiga L, Brambilla P, Pisani A, et al. Effect of longacting somatostatin analogue on kidney and cyst growth in autosomal dominant polycystic kidney disease (ALADIN): a randomised, placebo-controlled, multicentre trial. Lancet. 2013;382(9903):1485-95.

46. Chan PS, Nallamothu BK, Krumholz HM, Spertus JA, Li Y, Hammill BG, et al. Long-Term Outcomes in Elderly Survivors of In-Hospital Cardiac Arrest. N Engl J Med. 2013;368(11):1019-26.

47. Chew EY, Ambrosius WT, Davis MD, Danis RP, Gangaputra S, Greven CM, et al. Effects of medical therapies on retinopathy progression in type 2 diabetes. N Engl J Med. 2010;363(3):233-44.

48. Corbacioglu S, Cesaro S, Faraci M, Valteau-Couanet D, Gruhn B, Rovelli A, et al. Defibrotide for prophylaxis of hepatic veno-occlusive disease in paediatric haemopoietic stem-cell transplantation: an open-label, phase 3, randomised controlled trial. Lancet. 2012;379(9823):1301-9.

49. Day JN, Chau TTH, Wolbers M, Mai PP, Dung NT, Mai NH, et al. Combination Antifungal Therapy for Cryptococcal Meningitis. N Engl J Med. 2013;368 (14):1291-302.

50. De Ruyter JC, Olthof MR, Seidell JC, Katan MB. A Trial of Sugar-free or Sugar-Sweetened Beverages and Body Weight in Children. N Engl J Med. 2012;367(15):1397-406.

51. El Barzouhi A, Vleggeert-Lankamp C, Nijeholt L à, Geert J, Van DK, Van DH, et al. Magnetic Resonance Imaging in Follow-up Assessment of Sciatica. N Engl J Med. 2013;368(11):999-1007.

52. Farooq V, van Klaveren D, Steyerberg EW, Meliga E, Vergouwe Y, Chieffo A, et al. Anatomical and clinical characteristics to guide decision making between coronary artery bypass surgery and percutaneous coronary intervention for individual patients: development and validation of SYNTAX score II. Lancet. 2013;381(9867):639-50.

53. Feldman T, Foster E, Glower DD, Kar S, Rinaldi MJ, Fail PS, et al. Percutaneous Repair or Surgery for Mitral Regurgitation. N Engl J Med. 2011;364(15):1395-406

54. Free C, Knight R, Robertson S, Whittaker R, Edwards P, Zhou W, et al. Smoking cessation support delivered via mobile phone text messaging (txt2stop): A single-blind, randomised trial. Lancet. 2011;378(9785):49-55.

55. Funk LM, Weiser TG, Berry WR, Lipsitz SR, Merry AF, Enright AC, et al. Global operating theatre distribution and pulse oximetry supply: An estimation from reported data. Lancet. 2010;376(9746):1055-61.

56. Gadde KM, Allison DB, Ryan DH, Peterson CA, Troupin B, Schwiers ML, et al. Effects of low-dose, controlled-release, phentermine plus topiramate combination on weight and associated comorbidities in overweight and obese adults (CONQUER): a randomised, placebo-controlled, phase 3 trial. Lancet. 2011:377(9774):1341-52.

57. Gebre T, Ayele B, Zerihun M, Genet A, Stoller NE, Zhou Z, et al. Comparison of annual versus twice-yearly mass azithromycin treatment for hyperendemic trachoma in Ethiopia: a cluster-randomised trial. Lancet. 2012;379(9811):143-51.

58. Gill TM, Gahbauer EA, Han L, Allore HG. Trajectories of Disability in the Last Year of Life. N Engl J Med. 2010;362(13):1173-80.

59. Girotra S, Nallamothu BK, Spertus JA, Li Y, Krumholz HM, Chan PS. Trends in Survival after In-Hospital Cardiac Arrest. N Engl J Med. 2012;367(20):1912-20.

60. Gler MT, Skripconoka V, Sanchez-Garavito E, Xiao H, Cabrera-Rivero J, Vargas-Vasquez D, et al. Delamanid for Multidrug-Resistant Pulmonary Tuberculosis. N Engl J Med. 2012;366(23):2151-60.

61. Green J, Charman T, McConachie H, Aldred C, Slonims V, Howlin P, et al. Parent-mediated communication-focused treatment in children with autism (PACT): a randomised controlled trial. Lancet. 2010;375(9732):2152-60.

62. Green RC, Roberts JS, Cupples LA, Relkin NR, Whitehouse PJ, Brown T, et al. Disclosure of APOE Genotype for Risk of Alzheimer's Disease. N Engl J Med 2009;361(3):245-54.

63. Gupta J, Kai J, Middleton L, Pattison H, Gray R, Daniels J. Levonorgestrel intrauterine system versus medical therapy for menorrhagia. N Engl J Med. 2013;368(2):128-37.

64. Gutiérrez OM, Mannstadt M, Isakova T, Rauh-Hain J, Tamez H, Shah A, et al. Fibroblast Growth Factor 23 and Mortality among Patients Undergoing Hemodialysis. N Engl J Med. 2008;359(6):584-92.

65. Hanney M, Prasher V, Williams N, Jones EL, Aarsland D, Corbett A, et al. Memantine for dementia in adults older than 40 years with Down's syndrome (MEADOWS): a randomised, double-blind, placebo-controlled trial. Lancet. 2012;379(9815):528-36.

66. Hegarty K, O'Doherty L, Taft A, Chondros P, Brown S, Valpied J, et al. Screening and counselling in the primary care setting for women who have experienced intimate partner violence (WEAVE): a cluster randomised controlled trial. Lancet. 2013;382(9888):249-58. 
67. Hill JC, Whitehurst DG, Lewis M, Bryan S, Dunn KM, Foster NE, et al. Comparison of stratified primary care management for low back pain with current best practice (STarT Back): a randomised controlled trial. Lancet. 2011;378(9802):1560-71.

68. Holman RR, Farmer AJ, Davies MJ, Levy JC, Darbyshire JL, Keenan JF, et al. Three-year efficacy of complex insulin regimens in type 2 diabetes. $N$ Engl J Med. 2009;361(18):1736-47.

69. Hunt LP, Ben-Shlomo Y, Clark EM, Dieppe P, Judge A, MacGregor AJ, et al. 90-day mortality after 409096 total hip replacements for osteoarthritis, from the National Joint Registry for England and Wales: a retrospective analysis. The Lancet. 2013;382(9898):1097-104.

70. Jabre P, Belpomme V, Azoulay E, Jacob L, Bertrand L, Lapostolle F, et al. Family Presence during Cardiopulmonary Resuscitation. N Engl J Med. 2013;368(11):1008-18.

71. Jacobs AK, Normand ST, Massaro JM, Cutlip DE, Carrozza JP, Marks AD, et al. Nonemergency $\mathrm{PCl}$ at Hospitals with or without On-Site Cardiac Surgery. N Engl J Med. 2013;368(16):1498-508

72. Katz J, Lee AC, Kozuki N, Lawn JE, Cousens S, Blencowe H, et al. Mortality risk in preterm and small-for-gestational-age infants in low-income and middle-income countries: a pooled country analysis. Lancet. 2013;382 (9890):417-25.

73. Kelly HW, Sternberg AL, Lescher R, Fuhlbrigge AL, Williams P, Zeiger RS, et al. Effect of inhaled glucocorticoids in childhood on adult height. N Engl J Med. 2012;367(10):904-12.

74. Kessler D, Lewis G, Kaur S, Wiles N, King M, Weich S, et al. Therapist-delivered internet psychotherapy for depression in primary care: a randomised controlled trial. Lancet. 2009;374(9690):628-34

75. King G, Gakidou E, Imai K, Lakin J, Moore RT, Nall C, et al. Public policy for the poor? A randomised assessment of the Mexican universal health insurance programme. Lancet. 2009;373(9673):1447-54.

76. Kinmonth A, Wareham NJ, Hardeman W, Sutton S, Prevost AT, Fanshawe T, et al. Efficacy of a theory-based behavioural intervention to increase physical activity in an at-risk group in primary care (ProActive UK): a randomised trial. Lancet. 2008;371(9606):41-8.

77. Kirby MJ, Ameh D, Bottomley C, Green C, Jawara M, Milligan PJ, et al. Effect of two different house screening interventions on exposure to malaria vectors and on anaemia in children in The Gambia: a randomised controlled trial. Lancet. 2009:374(9694):998-1009.

78. Labrie J, Berghmans BLCM, Fischer K, Milani AL, Van DW, Smalbraak DJC, et al. Surgery versus Physiotherapy for Stress Urinary Incontinence. N Engl J Med. 2013;369(12):1124-33.

79. Lamb SE, Marsh JL, Hutton JL, Nakash R, Cooke MW. Mechanical supports for acute, severe ankle sprain: a pragmatic, multicentre, randomised controlled trial. Lancet. 2009:373(9663):575-81.

80. Lamb SE, Gates S, Williams MA, Williamson EM, Mt-Isa S, Withers EJ, et al. Emergency department treatments and physiotherapy for acute whiplash: A pragmatic, two-step, randomised controlled trial. Lancet. 2013;381(9866):546-56.

81. Lamb SE, Hansen Z, Lall R, Castelnuovo E, Withers EJ, Nichols V, et al. Group cognitive behavioural treatment for low-back pain in primary care: a randomised controlled trial and cost-effectiveness analysis. Lancet. 2010;375(9718):916-23.

82. Lawlor DA, Wills AK, Fraser A, Sayers A, Fraser WD, Tobias JH. Association of maternal vitamin $D$ status during pregnancy with bone-mineral content in offspring: a prospective cohort study. Lancet. 2013;381(9884):2176-83.

83. Lester RT, Ritvo P, Mills EJ, Kariri A, Karanja S, Chung MH, et al. Effects of a mobile phone short message service on antiretroviral treatment adherence in Kenya (WelTel Kenya1): a randomised trial. Lancet. 2010;376(9755):1838-45.

84. Lidegaard $\varnothing$, Løkkegaard E, Jensen A, Skovlund CW, Keiding N. Thrombotic stroke and myocardial infarction with hormonal contraception. N Engl J Med. 2012;366(24):2257-66

85. Liem S, Schuit E, Hegeman M, Bais J, De Boer K, Bloemenkamp K, et al. Cervical pessaries for prevention of preterm birth in women with a multiple pregnancy (ProTWIN): a multicentre, open-label randomised controlled trial. Lancet. 2013;382(9901):1341-9.

86. Lim SS, Stein DB, Charrow A, Murray CJ. Tracking progress towards universal childhood immunisation and the impact of global initiatives: a systematic analysis of three-dose diphtheria, tetanus, and pertussis immunisation coverage. Lancet. 2008:372(9655):2031-46.

87. Lo AC, Guarino PD, Richards LG, Haselkorn JK, Wittenberg GF, Federman DG, et al. Robot-Assisted Therapy for Long-Term Upper-Limb Impairment after Stroke. N Engl J Med. 2010;362(19):1772-83.
88. Lorenz MW, Polak JF, Kavousi M, Mathiesen EB, Völzke H, Tuomainen T, et al. Carotid intima-media thickness progression to predict cardiovascular events in the general population (the PROG-IMT collaborative project): A meta-analysis of individual participant data. Lancet. 2012;379(9831):2053-62.

89. Lu C, Schneider MT, Gubbins P, Leach-Kemon K, Jamison D, Murray CJ. Public financing of health in developing countries: a cross-national systematic analysis. Lancet. 2010;375(9723):1375-87.

90. Marcus CL, Moore RH, Rosen CL, Giordani B, Garetz SL, Taylor HG, et al. A Randomized Trial of Adenotonsillectomy for Childhood Sleep Apnea. N Engl J Med. 2013;368(25):2366-76.

91. Martin DF, Maguire MG, Ying G, Grunwald JE, Fine SL, Jaffe GJ. Ranibizumab and bevacizumab for neovascular age-related macular degeneration. N Engl J Med. 2011;364(20):1897-908.

92. Mauer M, Zinman B, Gardiner R, Suissa S, Sinaiko A, Strand T, et al. Renal and Retinal Effects of Enalapril and Losartan in Type 1 Diabetes. N Engl J Med. 2009;361(1):40-51.

93. May M, Boulle A, Phiri S, Messou E, Myer L, Wood R, et al. Prognosis of patients with HIV-1 infection starting antiretroviral therapy in sub-Saharan Africa: A collaborative analysis of scale-up programmes. Lancet. 2010;376 (9739):449-57.

94. McManus RJ, Mant J, Bray EP, Holder R, Jones MI, Greenfield S, et al. Telemonitoring and self-management in the control of hypertension (TASMINH2): a randomised controlled trial. Lancet. 2010;376(9736):163-72.

95. Melhuish E, Belsky J, Leyland AH, Barnes J. Effects of fully-established Sure Start Local Programmes on 3-year-old children and their families living in England: a quasi-experimental observational study. Lancet. 2008;372 (9650):1641-7.

96. Milstone AM, Elward A, Song X, Zerr DM, Orscheln R, Speck K, et al. Daily chlorhexidine bathing to reduce bacteraemia in critically ill children: a multicentre, cluster-randomised, crossover trial. Lancet. 2013;381 (9872):1099-106

97. Montalescot G, Zeymer U, Silvain J, Boulanger B, Cohen M, Goldstein P, et al. Intravenous enoxaparin or unfractionated heparin in primary percutaneous coronary intervention for ST-elevation myocardial infarction: the international randomised open-label ATOLL trial. Lancet. 2011;378 (9792):693-703.

98. Mozaffarian D, Shi P, Morris JS, Spiegelman D, Grandjean P, Siscovick DS, et al. Mercury Exposure and Risk of Cardiovascular Disease in Two U.S. Cohorts. N Engl J Med. 2011;364(12):1116-25.

99. Odd DE, Lewis G, Whitelaw A, Gunnell D. Resuscitation at birth and cognition at 8 years of age: a cohort study. Lancet. 2009;373(9675):1615-22.

100. Olanow CW, Rascol O, Hauser R, Feigin PD, Jankovic J, Lang A, et al. A Double-Blind, Delayed-Start Trial of Rasagiline in Parkinson's Disease. N Engl J Med. 2009;361(13):1268-78.

101. Pandharipande PP, Girard TD, Jackson JC, Morandi A, Thompson JL, Pun BT, et al. Long-Term Cognitive Impairment after Critical IIIness. N Engl J Med. 2013;369(14):1306-16.

102. Parker C, Waters R, Leighton C, Hancock J, Sutton R, Moorman AV, et al. Effect of mitoxantrone on outcome of children with first relapse of acute lymphoblastic leukaemia (ALL R3): an open-label randomised trial. Lancet. 2010;376(9757):2009-17.

103. Patel V, Weiss HA, Chowdhary N, Naik S, Pednekar S, Chatterjee S, et al. Effectiveness of an intervention led by lay health counsellors for depressive and anxiety disorders in primary care in Goa, India (MANAS): a cluster randomised controlled trial. Lancet. 2010;376(9758):2086-95.

104. Peek M, Mugford M, Tiruvoipati R, Wilson A, Allen E, Thalanany MM, et al. Efficacy and economic assessment of conventional ventilatory support versus extracorporeal membrane oxygenation for severe adult respiratory failure (CESAR): a multicentre randomised controlled trial. Lancet. 2009;374 (9698):1351-63.

105. Pimentel M, Lembo A, Chey WD, Zakko S, Ringel Y, Yu J, et al. Rifaximin Therapy for Patients with Irritable Bowel Syndrome without Constipation. N Engl J Med. 2011;364(1):22-32.

106. Price D, Musgrave SD, Shepstone L, Hillyer EV, Sims EJ, Gilbert RFT, et al. Leukotriene Antagonists as First-Line or Add-on Asthma-Controller Therapy. N Engl J Med. 2011;364(18):1695-707.

107. Pronyk PM, Muniz M, Nemser B, Somers M, McClellan L, Palm CA, et al. The effect of an integrated multisector model for achieving the Millennium Development Goals and improving child survival in rural sub-Saharan Africa: A non-randomised controlled assessment. Lancet. 2012;379(9832):2179-88. 
108. Puhan MA, Garcia-Aymerich J, Frey M, ter Riet G, Antó JM, Agustí AG, et al. Expansion of the prognostic assessment of patients with chronic obstructive pulmonary disease: the updated BODE index and the ADO index. Lancet. 2009:374(9691):704-11.

109. Roberts JD, Wells GA, Le May MR, Labinaz M, Glover C, Froeschl M, et al. Point-of-care genetic testing for personalisation of antiplatelet treatment (RAPID GENE): a prospective, randomised, proof-of-concept trial. Lancet. 2012;379(9827):1705-11.

110. Sitas F, Egger S, Bradshaw D, Groenewald P, Laubscher R, Kielkowski D, et al. Differences among the coloured, white, black, and other South African populations in smoking-attributed mortality at ages 35-74 years: a case-control study of 481640 deaths. Lancet. 2013;382(9893):685-93.

111. Smith KR, McCracken JP, Weber MW, Hubbard A, Jenny A, Thompson LM, et al. Effect of reduction in household air pollution on childhood pneumonia in Guatemala (RESPIRE): A randomised controlled trial. Lancet. 2011;378(9804):1717-26.

112. Solomon SD, Zile M, Pieske B, Voors A, Shah A, Kraigher-Krainer E, et al The angiotensin receptor neprilysin inhibitor LCZ696 in heart failure with preserved ejection fraction: a phase 2 double-blind randomised controlled trial. Lancet. 2012;380(9851):1387-95.

113. Sommers BD, Baicker $K$, Epstein AM. Mortality and access to care among adults after state medicaid expansions. N Engl J Med. 2012;367(11):1025-34.

114. Stanworth SJ, Estcourt LJ, Powter G, Kahan BC, Dyer C, Choo L, et al. A No-Prophylaxis Platelet-Transfusion Strategy for Hematologic Cancers. N Engl J Med. 2013;368(19):1771-80.

115. Sterne J, May M, Costagliola D, De Wolf F, Phillips AN, Harris R, et al. Timing of initiation of antiretroviral therapy in AIDS-free HIV-1-infected patients: a collaborative analysis of 18 HIV cohort studies. Lancet. 2009;373(9672):1352-63.

116. Strang J, Metrebian N, Lintzeris N, Potts L, Carnwath T, Mayet S, et al. Supervised injectable heroin or injectable methadone versus optimised oral methadone as treatment for chronic heroin addicts in England after persistent failure in orthodox treatment (RIOTT): a randomised trial. Lancet. 2010;375(9729):1885-95.

117. Subak LL, Wing R, West DS, Franklin F, Vittinghoff E, Creasman JM, et al. Weight Loss to Treat Urinary Incontinence in Overweight and Obese Women. N Engl J Med. 2009;360(5):481-90.

118. Tanser F, Bärnighausen T, Hund L, Garnett GP, McGrath N, Newell M. Effect of concurrent sexual partnerships on rate of new HIV infections in a high-prevalence, rural South African population: A cohort study. Lancet. 2011;378(9787):247-55.

119. Thabut G, Christie JD, Ravaud P, Castier $Y$, Brugière O, Fournier M, et al. Survival after bilateral versus single lung transplantation for patients with chronic obstructive pulmonary disease: a retrospective analysis of registry data. Lancet. 2008;371(9614):744-51.

120. Underwood M, Lamb SE, Eldridge S, Sheehan B, Slowther A, Spencer A, et al. Exercise for depression in elderly residents of care homes: a cluster-randomised controlled trial. Lancet. 2013;382(9886):41-9.

121. Vaucher YE, Peralta-Carcelen M, Finer NN, Carlo WA, Gantz MG, Walsh MC, et al. Neurodevelopmental outcomes in the early CPAP and pulse oximetry trial. N Engl J Med. 2012;367(26):2495-504.

122. Visco AG, Brubaker L, Richter HE, Nygaard I, Paraiso MFR, Menefee SA, et al. Anticholinergic Therapy vs. OnabotulinumtoxinA for Urgency Urinary Incontinence. N Engl J Med. 2012;367(19):1803-13.

123. Wadden TA, Volger S, Sarwer DB, Vetter ML, Tsai AG, Berkowitz Rl, et al. A Two-Year Randomized Trial of Obesity Treatment in Primary Care Practice. N Engl J Med. 2011;365(21):1969-79.

124. Walkup JT, Albano AM, Piacentini J, Birmaher B, Compton SN, Sherrill JT, et al. Cognitive Behavioral Therapy, Sertraline, or a Combination in Childhood Anxiety. N Engl J Med. 2008;359(26):2753-66.

125. Walz G, Budde K, Mannaa M, Nürnberger J, Wanner C, Sommerer C, et al. Everolimus in Patients with Autosomal Dominant Polycystic Kidney Disease. N Engl J Med. 2010;363(9):830-40.

126. Wang WC, Ware RE, Miller ST, lyer RV, Casella JF, Minniti CP, et al. Hydroxycarbamide in very young children with sickle-cell anaemia: a multicentre, randomised, controlled trial (BABY HUG). Lancet. 2011;377(9778):1663-72.

127. Weeks JC, Catalano PJ, Cronin A, Finkelman MD, Mack JW, Keating NL, et al. Patients' expectations about effects of chemotherapy for advanced cancer. N Engl J Med. 2012;367(17):1616-25.

128. Weintraub WS, Spertus JA, Kolm P, Maron DJ, Zhang Z, Jurkovitz C, et al. Effect of $\mathrm{PCl}$ on Quality of Life in Patients with Stable Coronary Disease. N Engl J Med. 2008;359(7):677-87.
129. Weiser TG, Regenbogen SE, Thompson KD, Haynes AB, Lipsitz SR, Berry WR, et al. An estimation of the global volume of surgery: a modelling strategy based on available data. Lancet. 2008;372(9633):139-44.

130. Westerlund $H$, Kivimäki M, Singh-Manoux A, Melchior M, Ferrie JE, Pentti J, et al. Self-rated health before and after retirement in France (GAZEL): a cohort study. Lancet. 2009;374(9705):1889-96.

131. Wherrett DK, Bundy B, Becker DJ, DiMeglio LA, Gitelman SE, Goland R, et al. Antigen-based therapy with glutamic acid decarboxylase (GAD) vaccine in patients with recent-onset type 1 diabetes: a randomised double-blind trial. Lancet. 2011;378(9788):319-27.

132. Wiles N, Thomas L, Abel A, Ridgway N, Turner N, Campbell J, et al. Cognitive behavioural therapy as an adjunct to pharmacotherapy for primary care based patients with treatment resistant depression: results of the CoBalT randomised controlled trial. Lancet. 2013;381(9864):375-84.

133. Yu H, Cowling BJ, Feng L, Lau EH, Liao Q, Tsang TK, et al. Human infection with avian influenza A H7N9 virus: an assessment of clinical severity. Lancet. 2013;382(9887):138-45.

134. Zeig-Owens R, Webber MP, Hall CB, Schwartz T, Jaber N, Weakley J, et al. Early assessment of cancer outcomes in New York City firefighters after the 9/11 attacks: an observational cohort study. Lancet. 2011;378(9794):898-905.

135. Gelman A, Van Mechelen I, Verbeke G, Heitjan DF, Meulders M. Multiple Imputation for Model Checking: Completed-Data Plots with Missing and Latent Data. Biometrics. 2005;1:74.

136. Abayomi K, Gelman A, Levy M. Diagnostics for multivariate imputations. J R Stat Soc: Ser C: Appl Stat. 2008;57(3):273-91.

137. He Y, Zaslavsky AM. Diagnosing imputation models by applying target analyses to posterior replicates of completed data. Stat Med. 2012;31(1):1-18.

138. Nguyen CD, Carlin JB, Lee KJ. Diagnosing problems with imputation models using the Kolmogorov-Smirnov test: a simulation study. BMC Med Res Methodol. 2013;13(1):1-18.

\section{Submit your next manuscript to BioMed Central and take full advantage of:}

- Convenient online submission

- Thorough peer review

- No space constraints or color figure charges

- Immediate publication on acceptance

- Inclusion in PubMed, CAS, Scopus and Google Scholar

- Research which is freely available for redistribution 